\title{
BMJ Open Forty years of shunt surgery at Rigshospitalet, Denmark: a retrospective study comparing past and present rates and causes of revision and infection
}

\author{
Philip Kofoed Månsson, Sofia Johansson, Morten Ziebell, Marianne Juhler
}

To cite: Kofoed Månsson $P$, Johansson S, Ziebell M, et al. Forty years of shunt surgery at Rigshospitalet, Denmark: a retrospective study comparing past and present rates and causes of revision and infection. BMJ Open 2017;7:e013389.

doi:10.1136/bmjopen-2016013389

- Prepublication history and additional material is available. To view please visit the journal (http://dx.doi.org/ 10.1136/bmjopen-2016013389).

Received 8 July 2016 Revised 10 October 2016 Accepted 21 October 2016

CrossMark

Department of Neurosurgery, Copenhagen University Hospital, Copenhagen, Denmark

Correspondence to Philip Kofoed Månsson; phmaans@hotmail.com

\section{ABSTRACT}

Objective: The objective of this study is to review our experience of shunt surgery by investigating 40 years of development in terms of rates of revision and infection, shunt survival and risk factors.

Design and participants: Medical records and operative reports were reviewed retrospectively for all patients who underwent primary shunt surgery at our department in the years 2010 to 2012. All results were compared with a previous study from our department. A mixed population consisting of 434 patients was included. Adults ( $\geq 15$ years) accounted for $89.9 \%$ of all patients and the mean follow-up time was 1.71 years.

Results: Overall, $42.6 \%$ had a revision of which $65.4 \%$ fell within 6 months postoperatively. Low age, high-risk diagnoses and less severe brain injury were associated with a higher risk of revision. One and 5 -year shunt survival probabilities were $66.2 \%$ (61.5-70.9) and 48.0\% (41.1-54.9). Within 4 weeks postoperatively, $3.2 \%$ had an infection and overall infection rate was $5.5 \%$. Short duration of surgery and the use of antibiotic prophylaxis were associated with a lower risk of infection. The most frequent causes of revision were valve defects $(18.4 \%)$ and proximal defects or obstructions $(15.7 \%)$. Compared to the previous study, no convincing improvement was found with regard to the revision rate ( $42.6 \%$ vs $48.3 \%$, p 0.060$)$ or overall infection rate $(5.5 \%$ vs $7.4 \%$, p 0.261).

Conclusions: Regardless of changes in patient demographics, techniques and equipment, risk of revision and infection still constitutes a major challenge in shunt surgery. The absence of convincing improvements calls for more studies concerning strategies to reduce complications.

\section{INTRODUCTION}

Shunting of the cerebrospinal fluid (CSF) remains the treatment of choice for the majority of patients with hydrocephalus.

\section{Strengths and limitations of this study}

- This is one of only very few studies concerning developments in outcomes for a mixed group of shunted patients reflecting the changing demographics over such a long period of time.

- In the attempt to make the new cohort comparable to the historic cohort, some definitions do not fit with a modern classification of patients with hydrocephalus.

- Since the objective was to compare the overall outcome for the entire group of shunted patients at different times, we omitted to exclude the few patients with ventriculoatrial-shunts and the relatively small number of children resulting in a heterogeneous group with subsequent limitations for the study conclusions.

Shunting of the CSF provides an immediate and effective treatment necessary to avoid the resulting neurological damage if the condition is left untreated. Unfortunately, shunt surgery is associated with an excessive rate of complications. For each patient this is reflected in the high risk of experiencing one or more reoperations. Together with the high incidence of hydrocephalus the treatment constitutes a significant medical and economic problem. ${ }^{1}$ At our department shunt-related surgery constitutes $14.1 \%$ of all neurosurgical procedures with primary insertions accounting for less than half of these. Therefore, it is a proclaimed goal to reduce the incidence of shunt revisions.

In 1995 and 1998 Borgbjerg et $a l^{2-4}$ published three papers emanating from our department concerning patients with primary shunt surgery from the period 1958 to 1989. Since then, several similar retrospective studies have reported comparable results according to rates of revision and 
infection, patient specific and intraoperative risk factors, and causes of shunt failure. ${ }^{5-12}$ Other studies have investigated the benefits of applying different procedural strategies ${ }^{13-15}$ and the use of specific shunt hardware to avoid certain complications in high-risk patients. ${ }^{16-18}$ Conversely, only few studies have addressed whether shunt surgery has improved over the past few decades resulting in decreased revision rates and prolonged shunt survival. Most of these studies conclude this does not seem to be the case ${ }^{19-21}$ while one study describes better outcomes for recently shunt-treated paediatric patients. ${ }^{22}$

The purpose of the present study is to evaluate trends in shunt surgery over decades by using two data sets generated in our department. This is achieved by comparing the published cohort 1958-1989 to a new group of patients with shunt surgery between 2010 and 12 in terms of (1) the rate of revision and risk factors for revision; (2) the rate of infection and risk factors for infection; (3) shunt survival time; and (4) frequent causes of shunt failure. Thus we have chosen the same parameters and largely the same statistics to facilitate comparison between the two cohorts.

\section{METHODS AND MATERIALS}

One author retrospectively reviewed the medical records and operative reports for all patients who underwent shunt surgery for hydrocephalus and related conditions at the Department of Neurosurgery, Rigshospitalet in the 3-year period between 1 January 2010 and 31 December 2012 with further 2 years of follow-up until 31 December 2014. If in the least doubt, the cause of revision was double-checked by a neurosurgeon blind to the procedure method and surgeon.

The Department of Neurosurgery at the University Hospital Rigshospitalet is the largest of four neurosurgical clinics in Denmark covering a population of 2.7 million people corresponding to $47 \%$ of the Danish population.

Initially, a total of 629 patients were identified in the operation planning system ORBIT with a procedural code for ventriculoperitoneal-shunt (KAAF05) or ventriculoatrial-shunt (KAAF15) surgery. The inclusion and exclusion of patients is shown in figure 1. Only patients with a primary shunt insertion were included. For all patients the information shown in box 1 was entered into a database.

\section{Definitions and classification}

The following definitions and classifications were to a large extent adapted from the 1958 to 1989 cohort by Borgbjerg et al. ${ }^{2-4}$

Diagnosis: Patients younger than 1 year of age were categorised as having (1) congenital hydrocephalus (shunt insertion within 4 weeks postnatal) or (2) infantile hydrocephalus (shunt insertion within the first year). Hydrocephalus in patients 1 year of age or older was

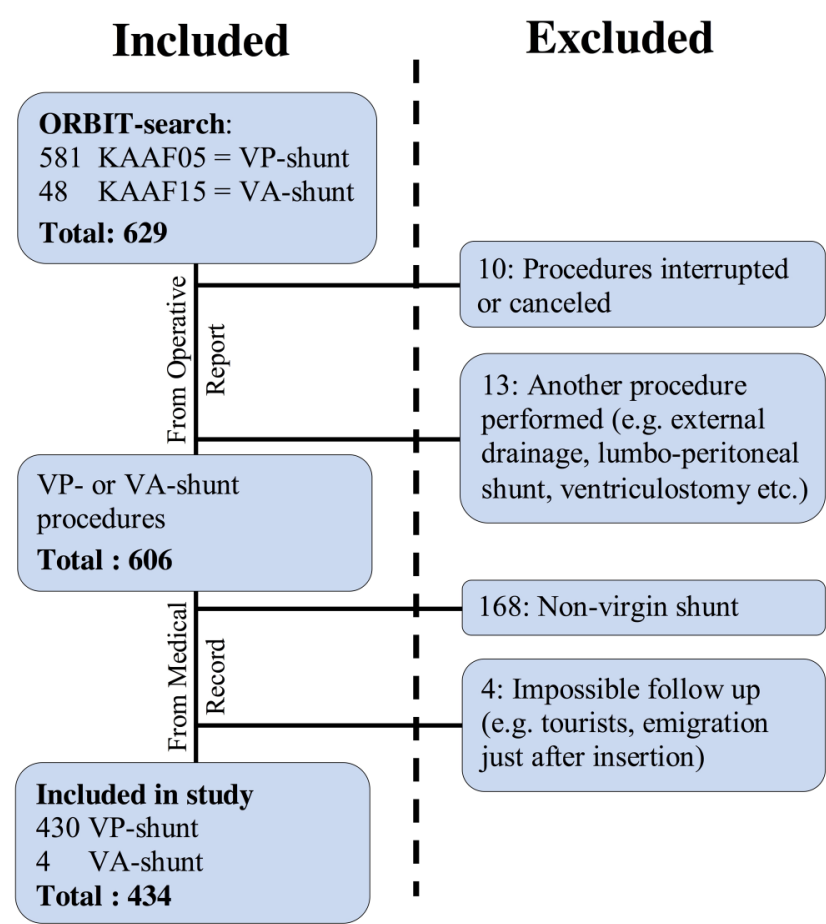

Figure 1 Flow chart presenting the inclusion and exclusion of patients. Reading the operative reports revealed that 23 patients did not undergo a CSF shunt procedure. A total of 168 patients were excluded because of previous shunt surgery and 4 patients were excluded because no follow-up information was available leaving 434 patients in the study. CSF, cerebrospinal fluid; VA-shunt, ventriculoatrial-shunt; VP-shunt, ventriculoperitoneal-shunt.

defined as acquired hydrocephalus and divided into (3) high-pressure hydrocephalus and (4) normal-pressure hydrocephalus. Patients with a demonstrated aqueductal stenosis were classified as (5) aqueductal stenosis regardless of age. In 10 cases, the information in the medical record was inadequate or the symptoms of the patient and diagnostic tests too divergent to fit into a diagnostic category. These patients were classified as (6) others.

Glasgow Coma Scale (GCS): Severity of brain injury before insertion was measured as GCS and divided into three groups: (1) GCS 14-15: mild or no injury (2) GCS 9-13: moderate injury (3) GCS 3-8: severe injury.

Surgeon: Three subgroups according to the surgeon's level of education were defined: A registrar was the youngest surgeon and not yet in a neurosurgical training programme. A trainee was a doctor in a neurosurgical training programme. The neurosurgeon was the most experienced and a specialist in neurosurgery.

Duration: Operations were divided into four groups according to the duration of surgery: (1) $<30 \mathrm{~min}$ (2) 30-59 min (3) 60-89 min and (4) $90 \mathrm{~min}$ or more.

Time of day: Time of surgery was classified as day (08:01 to $16: 00$.), evening (16:01 to 12:00.), or night (00:01 to $08: 00)$.

Antibiotics: In contrast to the historical study period, ${ }^{2}$ it was standard routine to administer antibiotic prophylaxis intraoperatively. 
Box 1 Information entered into Database

Patient specific information
date of birth
Information related to shunt insertion
age at insertion
distal shunt catheter placement
diagnosis
severity of brain injury
surgeon's educational level
duration of surgery
time of surgery
number of people in operating room
Information related to first revision
date of revision
Follow-up information
date of lost to follow-up
cause of lost to follow-up
repormation was extracted from the medical records, operative
perative documentation.
Cause of lost to follow-up was either dead or emigration.

Surgical findings: Only the first revision defined as the first shunt failure needing surgical intervention was included. We distinguished between: (1) proximal defect or obstruction; (2) proximal displacement; (3) distal defect or obstruction; (4) distal displacement; (5) valve defect; (6) over drainage; (7) acute infection (symptoms within 4 weeks after insertion); (8) late infection (symptoms later than postoperative week 4); (9) risk of infection/skin defect with exposed hardware; (10) no abnormal findings (despite clinical evidence of shunt failure, the entire system was found functioning intraoperative); and (11) others. Infection was defined according to the literature as clinical signs of peritonitis, septicaemia, meningitis or wound infection and biochemical or microbiological findings consistent with infection. ${ }^{29}$

\section{Statistical procedures}

Most data were categorical and analysed using $\chi^{2}$ tests reported with $\mathrm{p}$ values $\leq 0.05$ as the level of significance. All confident intervals reported were 95\% limits. In some cases, the $\chi^{2}$ test criteria were met by combining categories. In the case of antibiotic prophylaxis and risk of infection this was not possible; instead logistic regression was used in the analysis. In the case of ordered variables, when useful, the $\chi^{2}$ test was supplemented with the Mantel-Haenszel test for trend used as a more powerful test against a more restricted null hypothesis. ${ }^{23}$

Logistic regression was used to compare numerical variables on outcome variables and multiple logistic regression was used to determine independent risk factors for infection.

The Kaplan-Meier method of survival analysis was used to investigate shunt survival time including Log
Rank test to test for the influence on survival time of significant risk factors. To transfer the Kaplan-Meier plot by Borgbjerg et at into a new graph, the software package Engauge Digitizer was used.

Statistical software packages used were IBM SPSS Statistics V.22 and R V.3.1.3.

\section{RESULTS}

\section{Patient demographics and characteristics}

Patient demographics and characteristics are shown in table 1 . The age distribution of included patients is shown in figure 2; mean age was 54.4 years (median 61.0 years; range $0-94$ ) at the time of insertion.

Mean follow-up time was 1.71 years (median 1.53; range 0.00-4.94). 99 patients died within 2 years after insertion of which 35 had a revision. Further eight patients were censored in the follow-up period, six because of dead more than 2 years after insertion, 2 because of emigration. No deaths were related solely to shunt surgery but rather underlying diseases (eg, neoplasms, haemorrhages, trauma and for the older NPH patients also comorbidity).

The most common diagnosis was high-pressure hydrocephalus including $267(61.5 \%)$ patients. In recognition of the diversity in this large group, we further subdivided this group based on aetiology of hydrocephalus.

For 24 children the severity of brain injury was not measured or was inadequately described.

The majority of surgeries, that is $353(81.9 \%)$, were performed with five to six people in the operating room. The intraoperative documentation was missing in three cases.

Most patients either received antibiotic prophylaxis intraoperatively or were already receiving antibiotics at the time of insertion. In $44(10.1 \%)$ procedures antibiotics were by inscrutable reasons not administered.

\section{Rate of revision and risk factors}

Overall, $185(42.6 \%)$ patients had at least one revision (table 2). The majority of revisions $(65.4 \%)$ occurred within 6 months after shunt surgery. However, the mean time to first revision was 7.51 months reflecting that the main impact is made by early revisions, and late revisions only influence modestly. The following factors-experience of the surgeon ( $p$ 0.286), duration of surgery ( $p$ 0.467 ), time of day ( $\mathrm{p} 0.482$ ), and number of people in the operating room ( $p$ 0.416) - were not found to influence the rate of revision significantly.

Age of the patient was a significant risk factor for revision ( $p$ 0.005) with the highest rate among patients younger than 1 year of age at the time of shunt surgery. For patients younger than 15 years of age $(n=22+22=44)$ the rate of revision was $63.6 \%$ vs $40.3 \%$ in adults ( $p$ $0.005)$. As expected, the trend was significant ( $p 0.001$ ), with lower risk of revision with increasing age.

Subgroup analysis for 'diagnosis' was not possible because too few patients had a revision to meet the 
Table 1 Demographics and characteristics of patients

\begin{tabular}{|c|c|c|c|c|c|}
\hline \multirow[t]{2}{*}{ Total patients } & \multicolumn{5}{|c|}{$n=434$} \\
\hline & $\bar{n}$ & Per cent & & $\mathbf{n}$ & Per cent \\
\hline \multicolumn{3}{|l|}{ Age group (years) } & \multicolumn{3}{|l|}{ Level of brain injury } \\
\hline$<1$ & 22 & 5.1 & GCS $14-15$ & 251 & 61.2 \\
\hline $1-14$ & 22 & 5.1 & GCS 9-13 & 116 & 28.3 \\
\hline$\geq 15$ & 390 & 89.9 & GCS 3-8 & 43 & 10.5 \\
\hline \multicolumn{3}{|l|}{ Distal placement } & Missing & 24 & \\
\hline Atrial & 4 & 0.9 & \multicolumn{3}{|l|}{ Surgeon } \\
\hline Peritoneal & 430 & 99.1 & Registrar & 105 & 24.2 \\
\hline \multicolumn{3}{|l|}{ Diagnosis } & Trainee & 131 & 30.2 \\
\hline Congenital & 4 & 0.9 & Neurosurgeon & 198 & 45.6 \\
\hline Infantile & 16 & 3.7 & \multicolumn{3}{|l|}{ Duration (min) } \\
\hline $\mathrm{NPH}$ & 126 & 29.0 & $<30$ & 74 & 17.1 \\
\hline $\mathrm{HPH}$ & 267 & 61.5 & $30-59$ & 284 & 65.4 \\
\hline Posthaemorrhagic & 150 & & $60-89$ & 67 & 15.4 \\
\hline Space-occupying lesions & 67 & & $\geq 90$ & 9 & 2.1 \\
\hline Post-traumatic & 25 & & \multicolumn{3}{|l|}{ Time } \\
\hline $\mathrm{IIH}$ & 14 & & Day & 282 & 65.0 \\
\hline Postinfectious & 3 & & Evening & 140 & 32.3 \\
\hline Juvenile & 7 & & Night & 12 & 2.8 \\
\hline Others & 1 & & \multicolumn{3}{|l|}{$A B$ prophylaxis } \\
\hline Stenosis & 11 & 2.5 & Yes & 328 & 75.6 \\
\hline \multirow[t]{2}{*}{ Other } & 10 & 2.3 & No & 44 & 10.1 \\
\hline & & & In treatment & 62 & 14.3 \\
\hline \multicolumn{6}{|c|}{$\begin{array}{l}\text { The seven categories of HPH aetiology are italicized. Space-occupying lesions include } 59 \text { patients with malignant brain tumours, } 4 \text { patients } \\
\text { with benign intraventricular cysts and } 4 \text { patients with giant basilar aneurisms. IIH=idiopathic intracranial hypertension. Postinfectious include } \\
\text { patients with hydrocephalus secondary to meningitis. Juvenile include children with a demonstrated increased intracranial pressure without } \\
\text { any structural pathology on MRI. One patient did not fit into any of these categories. } \\
\text { AB prophylaxis, whether the patient receives antibiotic prophylaxis intraoperatively or is in a covering treatment; HPH, high-pressure } \\
\text { hydrocephalus; NPH, normal-pressure hydrocephalus; Stenosis, aqueductal stenosis. }\end{array}$} \\
\hline
\end{tabular}

Figure 2 Histogram showing the age distribution of patients at the time of primary shunt insertion. The bimodal distribution with a sharp peak $<1$ year of age and a broad peak covering the ages 48-80 years illustrates the occurrence of infantile hydrocephalus versus the dominance of NPH in the senior population. The low occurrence in the interim decades mainly contains cases with hydrocephalus related to other diseases; for example, $\mathrm{SAH}$, tumours and trauma. NPH, normal-pressure hydrocephalus; $\mathrm{SAH}$, subarchnoid haemorrhage.

criteria for the $\chi^{2}$ test. By defining a low-risk and highrisk diagnosis group, a higher risk of revision ( $p$ 0.037) among patients with congenital hydrocephalus, infantile hydrocephalus and aqueductal stenosis was revealed.

The effect of severity of brain injury had a significant influence on risk of revision with the trend being the more severe brain injury, the lower rate of revision $(p$ 0.018). However, a test of pairwise risk difference
Histogram - Age Distrubution

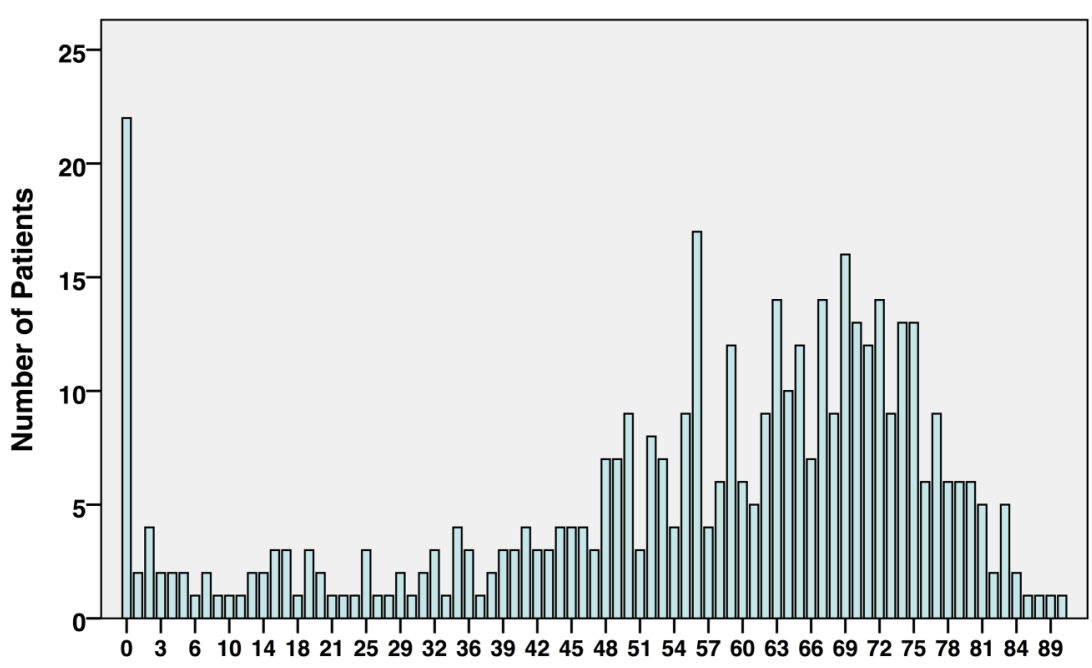

Age of Patient at Primary Shunt Surgery showed that the risk of revision was only significantly different from each other between the groups GCS 14-15 and GCS 9-13 ( p 0.009).

\section{Rate of infection and risk factors}

The majority of shunt-related infections (58.3\%) fell within the first four postoperative weeks. Fourteen (3.2\%) patients had an acute infection and overall, 
Table 2 Significant risk factors for shunt revision

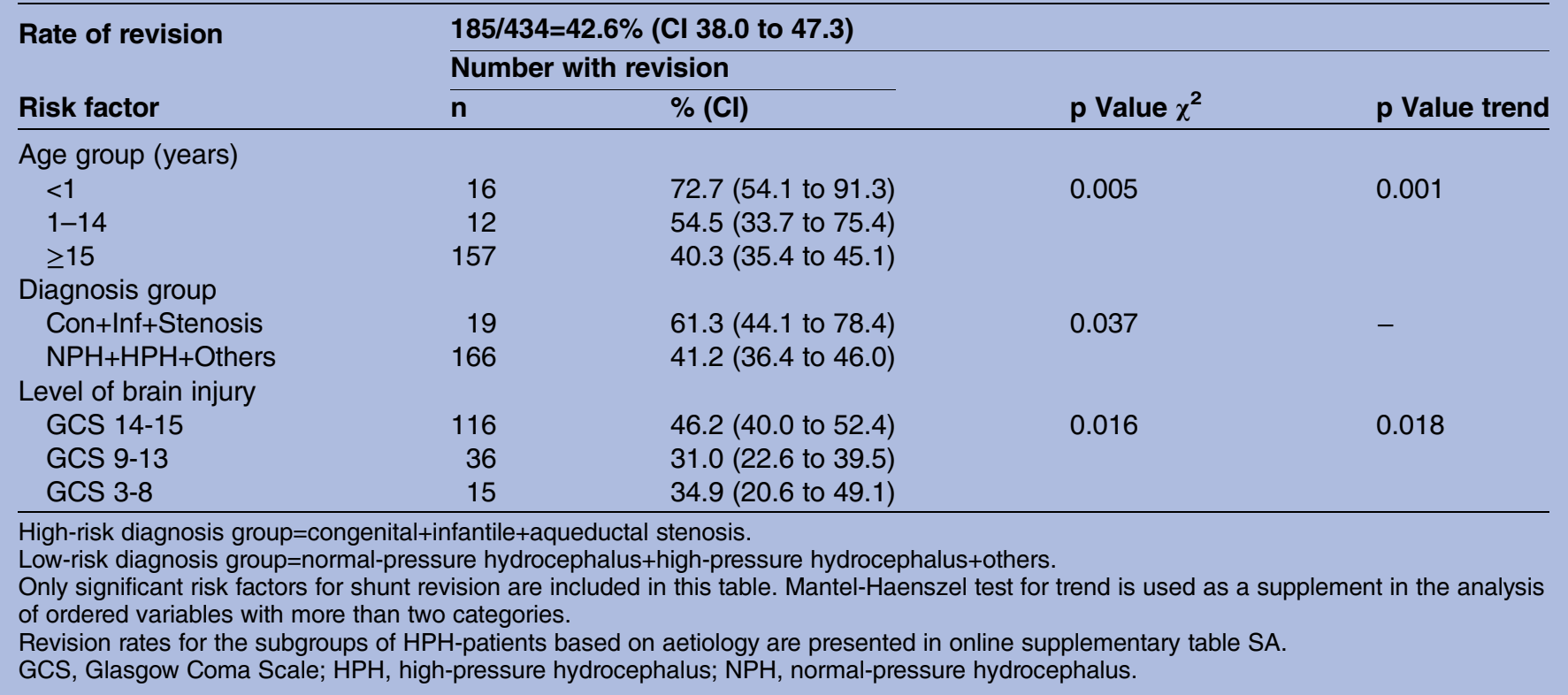

$24(5.5 \%)$ patients had an infection (table 3). In contrast to other studies, in our study our rate of infection was not influenced significantly by age. Among the 44 patients younger than 15 years of age no one had an infection at all $(0.0 \%)$, hence all 24 patients with infection were adults $(6.2 \%)$, but the numbers (22 below 1 year and 22 between 1 and 14 years) were too small for comparison ( $p$ 0.289); for example, just one case of infection in one of these groups would have changed the rate from 0 to $4.5 \%$. Other factors without significant influence on infection risk were low-risk or highrisk diagnosis group ( $\mathrm{p}$ 0.243), severity of brain injury ( $p$ 0.492) or time of day for the surgery ( $p$ 0.272).

Owing to the low number of patients with infection, some risk factor variables were combined for the analysis. Surgeons were said to be non-specialists if they are registrars or trainees. A lower risk of acute infection ( $\mathrm{p}$ $0.002)$ was observed among non-specialists $(0.8 \%)$ than among neurosurgeons $(6.1 \%)$.

The duration of surgery was combined in only two categories: short duration if $<60 \mathrm{~min}$ and long duration if

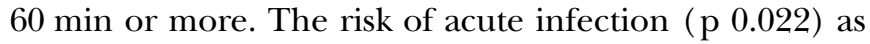
well as overall infection ( $p$ 0.050) was lower if surgery was performed in $<60 \mathrm{~min}$.

The effect of antibiotic prophylaxis was analysed using logistic regression. The categories (1) already receiving antibiotic and (2) antibiotic prophylaxis were combined in one group and compared to (3) no antibiotic prophylaxis. The odds of an acute infection were 5.43 times higher ( $p$ 0.004, table 4) with no antibiotic prophylaxis. The odds for an infection at any time was 5.19 ( $\mathrm{p}$ $<0.001)$ times higher without antibiotics.

Table 3 Significant risk factors for shunt infection

\begin{tabular}{|c|c|c|c|c|c|c|}
\hline \multirow{3}{*}{$\begin{array}{l}\text { Rate of acute infection } \\
\text { Rate of infection } \\
\text { Risk factor }\end{array}$} & \multicolumn{6}{|c|}{$\begin{array}{l}14 / 434=3.2 \%(C I 1.6 \text { to } 4.9) \\
24 / 434=5.5 \%(C I 3.4 \text { to } 7.7)\end{array}$} \\
\hline & \multicolumn{3}{|c|}{ Number with acute infection } & \multicolumn{3}{|c|}{ Number with infection } \\
\hline & $\bar{n}$ & Per cent $(\mathrm{Cl})$ & p Value $\chi^{2}$ & $\bar{n}$ & Per cent $(\mathrm{Cl})$ & p Value $\chi^{2}$ \\
\hline \multicolumn{7}{|l|}{ Surgeon group } \\
\hline Non-specialist & 2 & 0.8 (0 to 2.0$)$ & 0.002 & 9 & 3.8 (1.4 to 6.3$)$ & 0.096 \\
\hline Neurosurgeon & 12 & 6.1 (2.7 to 9.4$)$ & & 15 & 7.6 (3.6 to 11.3$)$ & \\
\hline \multicolumn{7}{|l|}{ Duration } \\
\hline Short $<60 \mathrm{~min}$ & 8 & $2.2(0.7$ to 3.8$)$ & 0.022 & 16 & 4.5 (2.3 to 6.6$)$ & 0.050 \\
\hline Long $\geq 60$ & 6 & 7.9 (1.8 to 14.0$)$ & & 8 & 10.5 (3.6 to 17.4$)$ & \\
\hline \multicolumn{7}{|l|}{ AB prophylaxis } \\
\hline Yes & 8 & $2.4(0.8$ to 4.1$)$ & 0.012 & 15 & 4.6 (2.3 to 6.8$)$ & 0.001 \\
\hline No & 5 & 11.4 (2.0 to 20.7$)$ & & 8 & 18.2 (6.8 to 29.6$)$ & \\
\hline In treatment & 1 & $1.6(0$ to 4.7$)$ & & 1 & $1.6(0$ to 4.7$)$ & \\
\hline
\end{tabular}

For $p=0.012$ and $p=0.001$ the $\chi^{2}$ test criteria were not met.

Only significant risk factors for acute infection or infection overall are included in this table. Valid and significant $\mathrm{p}$ values are in boldface. Non-specialist=registrar+trainee. 
Table 4 Analysis of risk factors for acute infection-univariate and multivariate analyses

\begin{tabular}{|c|c|c|c|c|c|c|}
\hline \multirow[b]{2}{*}{ Risk factor } & \multicolumn{3}{|c|}{$\begin{array}{l}\text { Logistic regression-effect of } \\
\text { single independent risk factor }\end{array}$} & \multicolumn{3}{|c|}{$\begin{array}{l}\text { Multiple logistic regression-effect } \\
\text { of each controlling for the others }\end{array}$} \\
\hline & $\overline{\text { OR }}$ & Cl for OR & p Value & $\overline{\text { OR }}$ & Cl for OR & p Value \\
\hline \multicolumn{7}{|l|}{ Surgeon group } \\
\hline Neurosurgeon vs Non-specialist & 7.55 & 1.67 to 34.15 & 0.009 & 15.35 & 2.98 to 79.17 & 0.001 \\
\hline \multicolumn{7}{|l|}{ Duration } \\
\hline Long $\geq 60 \mathrm{~min}$ vs Short $<60 \mathrm{~min}$ & 3.75 & 1.26 to 11.14 & 0.017 & 8.20 & 2.34 to 28.79 & 0.001 \\
\hline People in operating room & 0.57 & 0.28 to 1.17 & 0.124 & 0.64 & 0.31 to 1.30 & 0.22 \\
\hline \multicolumn{7}{|l|}{$A B$ prophylaxis } \\
\hline No $A B$ vs $A B+$ In treatment & 5.43 & 1.73 to 17.00 & 0.004 & 8.45 & 2.30 to 31.11 & 0.001 \\
\hline
\end{tabular}

Surgery performed by neurosurgeons had an OR for acute infection of 7.55 compared to non-specialists, this was despite the fact that they performed surgery faster than non-specialists $(p<0.001)$. Surgeries of longer duration carried an OR of 3.75 compared to short surgeries (table 4).

The number of people in operating room was not a significant predictor of acute infection, that is, OR 0.57 (p 0.124) (table 4).

Each risk factor was analysed controlling for the effect of the others using multiple logistic regression (right side of table 4). As shown, surgeon, duration and antibiotic prophylaxis were individual significant predictors of acute infection all with $\mathrm{p}$ values of 0.001 .

\section{Kaplan-Meier shunt survival}

The overall shunt survival curve of our study is presented in figure 3 together with the previous survival curve published in 1998. ${ }^{4}$ Mean survival time was 2.88 years (table 5 ). One and 5-year shunt survival

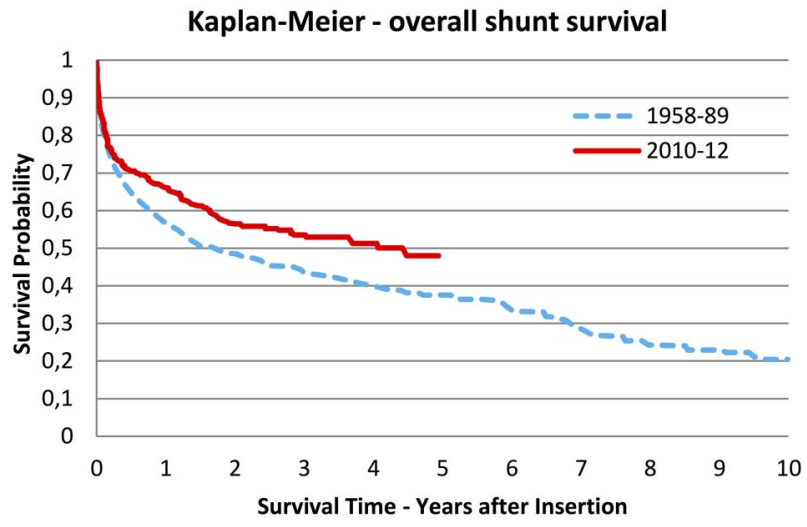

Figure 3 Kaplan-Meier plot of previous and present study showing the revision free shunt durability for all patients, $\mathrm{n}=884$ and $\mathrm{n}=434$ respectively. Note the difference in follow-up time resulting in disruption of the solid curve by time $=4.94$ years (maximum follow-up time in our study). With permission of Springer. ${ }^{4}$ probabilities were both higher in our study, although a test of significant difference was not performed due to the absence of raw data from the 1998 study.

We further looked for the influence on shunt survival by other variables. Patients younger than 1 year of age had a significantly ( $p$ 0.004) poorer survival curve than patients 15 years or older with no difference between the two older age groups, table 5 .

Patients belonging to the low-risk diagnosis group appeared to have longer shunt survival though the dif-

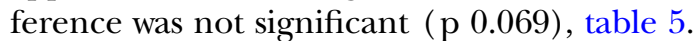

Survival curves for age groups and diagnosis groups are presented in the online supplementary figures S1 and S2.

\section{Surgical findings at first revision}

In table 6 , nine common causes of revision included in both studies are presented with proportions of all revisions $(\mathrm{n}=185)$ in our study. 'Other causes' artificially appears to be the most frequent but is due to its covering of three of our original causes not included in the previous study. ${ }^{3}$ Ignoring this, the most frequent cause of revision in our study was valve defects accounting for a significantly larger proportion of all revisions compared to the previous study $(10.5 \%$ vs $18.4 \%, \mathrm{p} 0.012)$. Proximal defect or obstruction was the second most frequent cause of revision $(15.7 \%)$ with the subunit disconnection accounting for $17(9.2 \%)$ revisions alone.

Among distal causes of revision, distal displacement was the main problem with the subunit subcutaneous displacement being the most frequent (7.6\%). Distal defect or obstruction had decreased significantly as a cause of

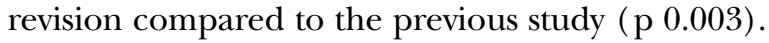

\section{Comparison with previous study}

The analysis of changes in significant patient demographics and characteristics revealed that proportionally more patients were adults in our study, which was also reflected in the lower proportion of high-risk diagnoses. More procedures were performed by registrars and 
Table 5 Kaplan-Meier analysis

\begin{tabular}{|c|c|c|c|c|}
\hline Study or risk factor & $\begin{array}{l}\text { Mean survival time } \\
\text { year }(\mathrm{Cl})\end{array}$ & $\begin{array}{l}\text { 1-year survival } \\
\text { Per cent }(\mathrm{Cl})\end{array}$ & $\begin{array}{l}\text { 5-year survival } \\
\text { Per cent }(\mathrm{Cl})\end{array}$ & Log rank $p$ Value \\
\hline \multicolumn{5}{|l|}{ Study } \\
\hline Present study 2010-2012 & 2.88 (2.66 to 3.10$)$ & 66.2 (61.5 to 70.9$)$ & 48.0 (41.1 to 54.9$)$ & - \\
\hline Previous study 1958-1989 & - & 57 (53 to 61$)$ & 37 (32 to 42$)$ & \\
\hline \multicolumn{5}{|l|}{ Age group (years) } \\
\hline$<1$ & $1.50(0.85$ to 2.15$)$ & 52.6 (31.2 to 74.0$)$ & & 0.004 \\
\hline $1-14$ & 2.27 (1.32 to 3.22$)$ & 52.9 (31.5 to 74.3$)$ & & \\
\hline$\geq 15$ & 2.98 (2.75 to 3.22$)$ & 67.9 (63.0 to 72.8$)$ & & \\
\hline \multicolumn{5}{|l|}{ Diagnosis group } \\
\hline Con+Inf+Stenosis & 1.98 (1.35 to 2.61$)$ & 60.1 (42.7 to 77.5$)$ & & 0.069 \\
\hline $\mathrm{NPH}+\mathrm{HPH}+$ Others & 2.94 (2.71 to 3.17$)$ & 66.8 (61.9 to 71.7$)$ & & \\
\hline \multicolumn{5}{|c|}{$\begin{array}{l}\text { Comparison of shunt survival in previous and present study—survival curves are shown in figure } 3 \text {. Log Rank test is used to test for a } \\
\text { significant influence on shunt survival of age group and diagnosis group in the present study. } \\
\text { p, } 0.004 \text { between }<1 \text { year and } \geq 15 \text { years; } p, 0.320 \text { between }<1 \text { year and } 1-14 \text { years; } p, 0.262 \text { between } 1-14 \text { years and } \geq 15 \text { years. } \\
\text { Time, } 4.94 \text { years is used to estimate the } 5 \text {-year shunt survival in our study. } \\
\text { HPH, high-pressure hydrocephalus; NPH, normal-pressure hydrocephalus. }\end{array}$} \\
\hline
\end{tabular}

Table 6 Surgical findings at first revision

\begin{tabular}{|c|c|c|c|c|}
\hline Cause of revision & $n=185$ & Per cent & & p Value \\
\hline $\begin{array}{l}\text { Proximal defect or } \\
\text { obstruction }\end{array}$ & 29 & 15.7 & & 0.169 \\
\hline Obstruction & 12 & 6.5 & & \\
\hline Disconnection & 17 & 9.2 & & \\
\hline Proximal displacement & 17 & 9.2 & & 0.657 \\
\hline $\begin{array}{l}\text { Distal defect or } \\
\text { obstruction }\end{array}$ & 7 & 3.8 & $\downarrow$ & 0.003 \\
\hline Distal displacement & 20 & 10.8 & & 0.301 \\
\hline Subcutaneous & 14 & 7.6 & & \\
\hline Radiating pain & 6 & 3.2 & & \\
\hline Valve defect & 34 & 18.4 & $\uparrow$ & 0.012 \\
\hline Acute infection & 14 & 7.6 & & 0.090 \\
\hline Late infection & 10 & 5.4 & & 0.128 \\
\hline No abnormal findings & 4 & 2.2 & & 0.984 \\
\hline Others & 50 & 27.0 & $\uparrow$ & 0.005 \\
\hline Over drainage & 24 & 13.0 & & \\
\hline $\begin{array}{l}\text { Risk of infection/ } \\
\text { wound }\end{array}$ & 7 & 3.8 & & \\
\hline Others & 19 & 10.3 & & \\
\hline
\end{tabular}

Proportion of all causes in present study increased $(\uparrow)$ or decreased $(\downarrow)$ compared to the previous study with corresponding $p$ values for significant difference. Significant $p$ values are en boldface.

The 19 causes classified as Others include: change to a different valve (6); shunt insertion into infected CSF (2); postoperative haemorrhage (2); haemorrhage not related to shunt (3); additional ventricle catheter (1); suspected infection without evidence (1); withdrawal (1); abdominal hernia (1); operational error (1); no description (1).

CSF, cerebrospinal fluid.

trainees in our study and in general, the procedures were performed faster; for specification see online supplementary table SB.

Data used in the analysis of any development since the 1958-1989 cohort, are presented in table 7 and reported as risk differences. The rate of revision of primary shunt surgery had not decreased significantly since the previous study period ( $p$ 0.060). This is in accordance with the only slightly different shunt-survival curves (figure 3) and the overlapping CIs for 5-year shunt survival (table 5). The insignificant trend towards lower risk of revision and longer shunt survival should be seen in the context of changed patients' demographics and risk factors.

As expected, the rate of acute infection had decreased significantly ( $p$ 0.037) but nonetheless the rate of overall infection had not decreased significantly ( p 0.261).

\section{DISCUSSION}

In this study we retrospectively presented data on shunt operated patients during the period 2010-2012 and compared this data to our own historical data collected 40 years ago. Overall, our study confirms some welldocumented risk factors for revision and infection. In addition, we had the opportunity to describe the development of shunt surgery at our department through the past four decades.

\section{Rate of revision and shunt survival}

In our study the overall rate of revision was significantly higher among children $(63.6 \%)$ than adults $(40.3 \%)$. Most revisions occurred within 6 months in accordance with the literature. ${ }^{4824}$

Not surprisingly, we found the rate of revision to be dependent on age and diagnosis as reported by others. $^{7}{ }^{11}$ Studies including both adults and children have reported rates of revision in the same range (23$46 \%)^{71012}$ as in our study. In studies including only adults, rates of revision has been reported to be 14$32 \% .^{524}$ In studies including only children, Berry et al ${ }^{11}$ found a revision rate of $37 \%$ and Stone et al found that $84.5 \%$ had a revision in their long-term follow-up study. The probability of 1 year shunt survival in our study was $66.2 \%$. In comparison, Hanlo et $a l^{12}$ and Cochrane and Kestle $^{25}$ have reported 1-year shunt survival probabilities 
Table 7 Comparison of previous and present study

\begin{tabular}{|c|c|c|c|c|}
\hline & $\begin{array}{l}\text { Previous study } \\
1958-1989, \%\end{array}$ & $\begin{array}{l}\text { Present study } \\
2010-2012, \%\end{array}$ & Risk difference \% (Cl) & p Value \\
\hline Revision & 48.3 & 42.6 & $-5.7(-11.5$ to 0.20$)$ & 0.060 \\
\hline Before 1970 & 58.4 & & $-15.8(-25.4$ to -6.1$)$ & 0.001 \\
\hline 1970-79 & 54.6 & & $-12.0(-19.3$ to -4.6$)$ & 0.001 \\
\hline 1980-89 & 33.7 & & 9.0 (2.1 to 15.8$)$ & 0.010 \\
\hline Infection & 7.4 & $5.5\left(4.1^{\star}\right)$ & $-1.8(-4.7$ to 1.1$)$ & $0.261\left(0.039^{\star}\right)$ \\
\hline Before 1970 & 2.7 & & 2.8 (-1.0 to 6.7$)$ & 0.238 \\
\hline 1970-79 & 8.6 & & $-3.1(-7.0$ to 0.9$)$ & 0.126 \\
\hline 1980-89 & 8.0 & & $-2.5(-6.2$ to 1.2$)$ & 0.192 \\
\hline Acute infection & 6.1 & 3.2 & $-2.9(-5.3$ to -0.42$)$ & 0.037 \\
\hline \multicolumn{5}{|c|}{$\begin{array}{l}\text { Pairwise comparison of the proportions is reported as risk difference with related } p \text { values indicating significant difference or not. } \\
\text { *To estimate the effect of antibiotic prophylaxis, all patients in present study with no antibiotic prophylaxis ( } \mathrm{n}=44 \text { ) were excluded resulting in a } \\
\text { significant difference ( } \mathrm{p} 0.039 \text { ) in risk of infection for all patients who followed the current regimen. } \\
\text { As well as comparing the } 2010-2012 \text { cohort with the entire } 1958-1989 \text { cohort, the new cohort is compared to three individual time periods in } \\
\text { the previous study and presented in the table in italics. The rate of revision was significantly higher ( } \mathrm{p} 0.001) \text { in the first two time periods } \\
\text { compared to the } 2010-2012 \text { cohort, but it was significantly lower in the latest decade }(\mathrm{p} 0.010) \text {. Though the rate of infection was remarkably } \\
\text { lower in the earliest time period, compared to the } 2010-2012 \text { cohort none of the three time periods had a significantly different rate of } \\
\text { infection. }\end{array}$} \\
\hline
\end{tabular}

of $71 \%$ and $59 \%$, respectively, and Reddy et $a l^{7}$ reported significantly shorter shunt survival in paediatric patients consistent with our findings.

The lower rate of revision observed among patients with more severe brain injury is most likely the result of these patients' shorter survival time and inability to report symptoms of shunt failure.

Discrepancies in reported rates of revision among studies are probably a combined result of actual differences and different study designs including differences in follow-up time and patients demographics, for example, the age composition would influence the results significantly. Another challenge of comparing revision rates is the influence of different aetiologies that has been shown to be significantly associated with shunt revisions. ${ }^{5} 72627$

Only few studies have considered whether the improvement in materials and techniques through the past few decades has resulted in better outcomes for shunt treated patients. Compared to the previous study from our department, the difference in revision rates from $48.3 \%$ to $42.6 \%$ was not statistically significant. The changed demographics with fewer children and fewer high-risk diagnoses in our study may have caused a reduction itself.

Molina et $a l^{19}$ and Drake et $a l^{21}$ reported that new shunt systems were not better than old systems and a review by Stein et $a t^{20}$ showed no improvement in revision rates over the past few decades. In contrast, Kulkarni et $a l^{22}$ compared two cohorts of paediatric patients with primary shut surgery in 1993-1999 and 2008-2012, respectively, and found a significantly longer shunt survival for the 2008-2012 cohort.

While study conclusions regarding positive development or not are based mainly on the presence of significant $p$ values, which depends highly on study design and patient volume, the overall trend seems to be a lack of convincing improvement in shunt surgery. This absence of improvement consistent with our results must be compared to the development of other surgical procedures. For example, the 10-year revision free probability of total hip replacements has increased from about $85 \%$ in 1979 to about $95 \%$ for procedures performed in 2004 according to The Swedish Hip Arthroplasty Register's annual report $2013^{28}$ and Herberts and Malchau. ${ }^{29}$ Similar development has been reported by cardiologists performing heart valve replacements. Hokken et $a l^{30}$ reported a lower risk of early mortality following aortic heart valve replacement, that is, $\mathrm{OR}=0.2$ for procedures performed in 1990 vs 1970 despite increased proportion of high-risk patients. Similar developments are reported by Feyrer $e t a l^{31}$ and The Society of Cardiothoracic Surgeons of Great Britain and Ireland. ${ }^{32}$

One important consideration to make is whether decreasing the rate of shunt revision is the right measure of success as indicated by Di Rocco et al. ${ }^{33}$ Since the overall objective is to achieve a better treatment for patients with hydrocephalus, the introduction of new surgical procedures for patients with hydrocephalus such as third ventriculostomy can result in a persistently high rate of revisions among shunt-treated patients, however, with better outcomes for the total group of patients with hydrocephalus.

To point out reasons for the lack of improvement is beyond the scope of this study, but a rapid implementation and ongoing evaluation of new techniques, shunt materials and individualised treatment strategies may be a part of the solution. According to Herberts and Malchau, ${ }^{29}$ the ongoing evaluation of best practices and implants provided by The Swedish Hip Arthroplasty Register has been a major contributor to the development seen in Sweden. The same position is advocated by Larsson et $a l^{34}$ who argue that the implementation of disease registries has the possibility to lower health costs due to fewer reoperations and complications. So far, there are no publications from shunt registries 
demonstrating a similar complication reducing effect on shunt surgery.

\section{Infection and antibiotic prophylaxis}

Postoperative shunt-related infections have been considered a major problem of shunt surgery due to its significant consequences for the patient and as a complication costly to treat. Despite the positive development in techniques and procedures to prevent infection through the past few decades, the problem still deserves our attention.

Overall, $24(5.5 \%)$ patients in our study had an infection of which $14(3.2 \%)$ fell within 4 weeks postoperatively. This is in the lower range of others published findings, which may be influenced by the fact that we included only primary shunt insertions into our study and revision procedures have been shown to have a higher rate of infection. ${ }^{10}{ }^{35}$ The rate of revision was $6.2 \%$ for adults and $0.0 \%$ for children. Studies including both adults and children and primary insertions as well as revisions have reported per procedure infection rates of $6.1 \%, 7.2 \%$ and $8.3 \% .^{9} 10$ 12 For paediatric patients per procedure infection rates have been reported by Piatt $e t a l^{6}$ who found $2.0 \%$ to have an infection within 30 days postoperatively and Cochrane and Kestle ${ }^{25}$ found $8.6 \%$ to have an infection. A significantly lower risk of acute infection was observed compared to the previous study from our department. ${ }^{2}$ The reduction of overall infection risk was not significant.

In accordance with other studies we found the infection rate to depend on antibiotic prophylaxis, duration of surgery, ${ }^{10}$ and the risk of acute infection further depended on the surgeon's experience.

In 1995 Borgbjerg et $a l^{2}$ concluded that intraoperative antibiotic prophylaxis was still controversial. We found the OR for infection without the use of antibiotics to be as high as 8.45 for acute infection and 6.18 for infection overall, that is, antibiotics have a greater effect on acute infection. In comparison, large meta-analytic publications report an OR for overall infection of $\sim 2$ by the use of antibiotics. ${ }^{36} 37$ This indicates that other patientrelated and surgery-related factors than antibiotic prophylaxis may account for the difference in infection OR between our studies and other studies, but our data do not permit us to define these.

Efforts to further reduce the infection risk include the application of strict protocols including all known risk factors. Choux $e t a l^{88}$ and Kestle $e t a l^{\beta 9}$ have reported admirable results by the application of relatively simple protocols including focus on prophylaxis, signs on the door to reduce traffic, focus on hand scrub, few people in the operating room etc to reduce infection risk in children. Prospective studies evaluating such protocols under different settings are needed.

The theory behind the association of number of personnel in the operating room and infection is based on correlation between number of persons and air contamination. ${ }^{40}$ Reducing the number of people has been part of successful protocols to reduce infection. ${ }^{38}$ It should be mentioned that a lot of contributing factors to air contamination were not measured, for example, level of conversation and traffic in the room. Additionally, only very few operations were performed with more than six people making it difficult to detect any contribution to infection risk.

Surgeon's experience has been defined in different ways. For example, Cochrane and Kestle ${ }^{41}$ found the number of procedures performed by each surgeon in the study period to influence infection rate with more experienced surgeons having lower risk of infection. In contrast, we found that non-specialists-the more inexperienced surgeons who performed surgery slower-had a lower rate of acute infection than the neurosurgeons, which is also the opposite of what Borgbjerg et $a l^{2}$ reported. This indicates that procedure routine rather than 'rank' of the surgeon might be a better measure for surgical skills and several underlying confounders must have influenced our result.

\section{Causes of revision}

Knowledge about the most frequent causes of shunt failure is a prerequisite for targeting the effort to reduce revisions. In our study the most frequent causes of revision were valve defects $(18.4 \%)$, proximal defect or obstruction $(15.7 \%)$ including disconnection $(9.2 \%)$, over drainage $(13.0 \%)$, distal displacement $(10.8 \%)$ and proximal displacement $(9.2 \%)$. Similar results reported by other authors may have been influenced by variation in classification of causes, demographic factors like age, diagnoses and aetiology and whether revisions procedures were included for analysis. By recalculating the results, three studies, ${ }^{8} 1012$ all including revisions, reported proximal obstruction to constitute $14-27 \%$ of all revisions, disconnection $1.5-11 \%$, valve defect 8 $18.4 \%$ and two studies ${ }^{10}{ }^{12}$ reported over drainage to constitute $5.1-11 \%$ of revisions.

Compared to the 1958-1989 cohort, $^{3}$ valve defects constitute a significantly higher proportion of revision causes while distal defects and obstructions constitute a significantly smaller proportion.

Several studies have investigated specific actions to reduce individual failures. Proximal obstruction is a persistent challenge in shunt surgery. The importance of accurate proximal catheter placement to reduce proximal obstruction has been described by Janson et $a l^{14}$ and several authors have reported beneficial effect of the use of intraoperative imaging in the accuracy of proximal catheter placement and proximal shunt failure rates, though some of these studies fail to improve overall shunt failure rate. ${ }^{14} 154243$ Prospective studies applying known strategies to reduce specific complications in high-risk patients are desired in the development towards more patient-specific treatments.

\section{Limitations}

Owing to its retrospective design this study has several limitations. Decision-making about shunt insertion and 
revision was influenced by individual surgeons. Some of the clinical variables were not described in a standardised way, but were extracted from surgical notes and charts. Furthermore, some variables were not included for analysis, for example, valve type and aetiology was only considered for the patients with high-pressure hydrocephalus.

Despite the limitations, the retrospective design has the opportunity to analyse how shunt treatment has evolved over decades in a large patient sample contributing to increased study power. The often limiting problem of lost to follow-up is most likely reduced to a minimum in our study because of the comprehensive national registration in Denmark of health data, death, emigration and the electronic medical report including all contacts with healthcare providers in a specific region which enables us to follow all patients whether hospitalised or not.

\section{CONCLUSIONS}

This retrospective study reveals a substantial number of patients experiencing shunt revisions following primary shunt insertion. Though patient demographics have changed with fewer children resulting in fewer high-risk patients in the new 2010-2012 cohort, the rate of revision has not decreased through the past four decades and remains above $40 \%$. The odds of an acute infection is 8.45 times higher without the use of antibiotic prophylaxis and the implementation of antibiotic prophylaxis might be the most important contributor to the significant reduction in acute infection. The risk of overall infection has not decreased significantly.

Our findings fit well with the current literature and at the same time emphasise the need for improved techniques, equipment and shunt materials to reduce the rate of complications. Future prospective studies must confirm causal risk factors and further evaluate the benefits of applying a more patient-specific strategy to reduce revision rates.

Acknowledgements The authors gratefully acknowledge Kasper Brink-Jensen, $\mathrm{PhD}$ for his valuable comments on the statistics and Lars Kristian Hebsgaard Jessen for proofreading of the manuscript.

Contributors SJ made a preliminary smaller scale study and thus contributed significantly to the concept of this study. Data collecting was performed by PKM under the supervision of MZ and MJ. The statistical analysis was performed by PKM and interpreted in corporation with MZ and MJ. All authors have critically revised the manuscript.

Funding This work was supported by The Lundbeck Foundation in the form of a scholarship for a total of 140000 DKK to the first author. The sponsor had no role in the design or conduct of this research.

Competing interests All authors have completed the ICMJE uniform disclosure form at http://www.icmje.org/coi_disclosure.pdf and declare: PKM received financial support from The Lundbeck Foundation.

Ethics approval This study was approved by the Danish Health and Medicines Authority with prior permission from the Danish Data Protecting Agency for the handling of personal data.

Provenance and peer review Not commissioned; externally peer reviewed.
Data sharing statement No additional data are available.

Open Access This is an Open Access article distributed in accordance with the Creative Commons Attribution Non Commercial (CC BY-NC 4.0) license, which permits others to distribute, remix, adapt, build upon this work noncommercially, and license their derivative works on different terms, provided the original work is properly cited and the use is non-commercial. See: http:// creativecommons.org/licenses/by-nc/4.0/

\section{REFERENCES}

1. Patwardhan RV, Nanda A. Implanted ventricular shunts in the United States: the billion-dollar-a-year cost of hydrocephalus treatment. Neurosurgery 2005;56:139-44. discussion 44-5.

2. Borgbjerg BM, Gjerris F, Albeck MJ, et al. Risk of infection after cerebrospinal fluid shunt: an analysis of 884 first-time shunts. Acta Neurochir (Wien) 1995;136:1-7.

3. Borgbjerg BM, Gjerris F, Albeck MJ, et al. Frequency and causes of shunt revisions in different cerebrospinal fluid shunt types. Acta Neurochir (Wien) 1995;136:189-94.

4. Borgbjerg BM, Gjerris F, Albeck MJ, et al. A comparison between ventriculo-peritoneal and ventriculo-atrial cerebrospinal fluid shunts in relation to rate of revision and durability. Acta Neurochir (Wien) 1998;140:459-64. discussion 65.

5. Khan F, Rehman A, Shamim MS, et al. Factors affecting ventriculoperitoneal shunt survival in adult patients. Surg Neurol Int 2015;6:25

6. Piatt JH Jr. Thirty-day outcomes of cerebrospinal fluid shunt surgery: data from the National Surgical Quality Improvement Program-Pediatrics. J Neurosurg Pediatr 2014;14:179-83.

7. Reddy GK, Bollam P, Caldito G. Long-term outcomes of ventriculoperitoneal shunt surgery in patients with hydrocephalus. World Neurosurg 2014;81:404-10.

8. Stone JJ, Walker CT, Jacobson M, et al. Revision rate of pediatric ventriculoperitoneal shunts after 15 years. J Neurosurg Pediatr 2013;11:15-9.

9. Reddy GK, Bollam P, Caldito G. Ventriculoperitoneal shunt surgery and the risk of shunt infection in patients with hydrocephalus: long-term single institution experience. World Neurosurg 2012;78:155-63.

10. Korinek AM, Fulla-Oller L, Boch AL, et al. Morbidity of ventricular cerebrospinal fluid shunt surgery in adults: an 8-year study. Neurosurgery 2011;68:985-94. discussion 94-5.

11. Berry JG, Hall MA, Sharma V, et al. A multi-institutional, 5-year analysis of initial and multiple ventricular shunt revisions in children. Neurosurgery 2008;62:445-53. Discussion 53-4.

12. Hanlo PW, Cinalli G, Vandertop WP, et al. Treatment of hydrocephalus determined by the European Orbis Sigma Valve I survey: a multicenter prospective 5-year shunt survival study in children and adults in whom a flow-regulating shunt was used. J Neurosurg 2003;99:52-7.

13. Pinto FC, de Oliveira MF. Laparoscopy for ventriculoperitoneal shunt implantation and revision surgery. World J Gastrointest Endosc 2014;6:415-18.

14. Janson CG, Romanova LG, Rudser KD, et al. Improvement in clinical outcomes following optimal targeting of brain ventricular catheters with intraoperative imaging. J Neurosurg 2014; 120:684-96

15. Crowley RW, Dumont AS, Asthagiri AR, et al. Intraoperative ultrasound guidance for the placement of permanent ventricular cerebrospinal fluid shunt catheters: a single-center historical cohort study. World Neurosurg 2014;81:397-403.

16. Lee L, King NK, Kumar D, et al. Use of programmable versus nonprogrammable shunts in the management of hydrocephalus secondary to aneurysmal subarachnoid hemorrhage: a retrospective study with cost-benefit analysis. J Neurosurg 2014:121:899-903.

17. Xu H, Wang ZX, Liu F, et al. Programmable shunt valves for the treatment of hydrocephalus: a systematic review. Eur $\mathrm{J}$ Paediatr Neurol 2013;17:454-61

18. Zachenhofer I, Donat M, Roessler K. The combination of a programmable valve and a subclavicular anti-gravity device in hydrocephalus patients at high risk for hygromas. Neurol Res 2012;34:219-22.

19. Molina ME, Lema A, Palacios MG, et al. [25 year's experience in cerebrospinal shunt. Are new systems better?]. Cir Pediatr 2008:21:223-7.

20. Stein SC, Guo W. Have we made progress in preventing shunt failure? A critical analysis. J Neurosurg Pediatr 2008;1:40-7. 
21. Drake JM, Kestle JR, Milner R, et al. Randomized trial of cerebrospinal fluid shunt valve design in pediatric hydrocephalus. Neurosurgery 1998;43:294-303. discussion 303-5.

22. Kulkarni AV, Riva-Cambrin J, Butler J, et al. Outcomes of CSF shunting in children: comparison of Hydrocephalus Clinical Research Network cohort with historical controls: clinical article. J Neurosurg Pediatr 2013;12:334-8.

23. Kirkwood BR, Sterne JAC. Essential medical statistics. 2nd edn. Malden, MA. Blackwell Science, 2003:165-76.

24. Reddy GK, Bollam P, Shi R, et al. Management of adult hydrocephalus with ventriculoperitoneal shunts: long-term single-institution experience. Neurosurgery 2011;69:774-80. discussion 80-1.

25. Cochrane DD, Kestle J. Ventricular shunting for hydrocephalus in children: patients, procedures, surgeons and institutions in English Canada, 1989-2001. Eur J Pediatr Surg 2002;12(Suppl 1):S6-11.

26. Reddy GK. Ventriculoperitoneal shunt surgery and the incidence of shunt revision in adult patients with hemorrhage-related hydrocephalus. Clin Neurol Neurosurg 2012;114:1211-6.

27. Reddy GK, Bollam P, Caldito G, et al. Ventriculoperitoneal shunt complications in hydrocephalus patients with intracranial tumors: an analysis of relevant risk factors. J Neurooncol 2011;103: 333-42.

28. Garellick G, Kärrholm J, Lindahl H, et al. The Swedish Hip Arthroplasty Register: Annual Report. 2013. p 94 and 106. http:// www.shpr.se/Libraries/Documents/AnnualReport_2013Eng.sflb.ashx (accessed Jun 2015)

29. Herberts $\mathrm{P}$, Malchau $\mathrm{H}$. Long-term registration has improved the quality of hip replacement: a review of the Swedish THR Register comparing 160,000 cases. Acta Orthop Scand 2000;71:111-21.

30. Hokken RB, Steyerberg EW, Verbaan N, et al. 25 years of aortic valve replacement using mechanical valves. Risk factors for early and late mortality. Eur Heart $J$ 1997; 18:1157-65.

31. Feyrer R, Lott $S$, Englmann $P$, et al. Results of a 1 to 31 years follow-up after aortic valve replacement in 2327 patients. J Cardiovasc Surg (Torino) 1996;37(Suppl 1):17-22.
32. The Society of Cardiothoracic Surgeons of Great Britain and Ireland. Fifth National Adult Cardiac Surgical Database Report 2003Improving outcomes for patients. 42-3. http://www.scts.org/ userfiles/resources/5thBlueBook2003.pdf (accessed Jun 2015).

33. Di Rocco C, Conforti G, Caldarelli M. The current minor perception of V-S complication. World Neurosurg 2014;81:285-7.

34. Larsson S, Lawyer P, Garellick G, et al. Use of 13 disease registries in 5 countries demonstrates the potential to use outcome data to improve healthcare's value. Health Aff (Millwood) 2012;31: $220-7$.

35. Simon TD, Butler J, Whitlock KB, et al. Risk factors for first cerebrospinal fluid shunt infection: findings from a multi-center prospective cohort study. J Pediatr 2014;164:1462-8.e2.

36. Ratilal B, Costa J, Sampaio C. Antibiotic prophylaxis for surgical introduction of intracranial ventricular shunts: a systematic review. J Neurosurg Pediatr 2008;1:48-56.

37. Langley JM, LeBlanc JC, Drake J, et al. Efficacy of antimicrobial prophylaxis in placement of cerebrospinal fluid shunts: meta-analysis. Clin Infect Dis 1993;17:98-103.

38. Choux M, Genitori L, Lang D, et al. Shunt implantation: reducing the incidence of shunt infection. J Neurosurg 1992;77:875-80.

39. Kestle JR, Riva-Cambrin J, Wellons JC III, et al. A standardized protocol to reduce cerebrospinal fluid shunt infection: the Hydrocephalus Clinical Research Network Quality Improvement Initiative. J Neurosurg Pediatr 2011;8:22-9.

40. Hambraeus A, Laurell G. Protection of the patient in the operating suite. J Hosp Infect 1980;1:15-30.

41. Cochrane DD, Kestle JR. The influence of surgical operative experience on the duration of first ventriculoperitoneal shunt function and infection. Pediatr Neurosurg 2003;38:295-301.

42. Wilson TJ, Stetler WR Jr, Al-Holou WN, et al. Comparison of the accuracy of ventricular catheter placement using freehand placement, ultrasonic guidance, and stereotactic neuronavigation. J Neurosurg 2013;119:66-70.

43. Hayhurst C, Beems T, Jenkinson MD, et al. Effect of electromagnetic-navigated shunt placement on failure rates: a prospective multicenter study. J Neurosurg 2010;113:1273-8. 